\title{
Novel sensor for long-term monitoring of ammonia in gas phase
}

\author{
Kornelia Gawlitza ${ }^{1}$, Carlo Tiebe ${ }^{2}$, Ulrich Banach², Reinhard Noske ${ }^{3}$, Matthias Bartholmai², Knut \\ Rurack $^{1}$ \\ ${ }^{1}$ Div. 1.9 Sensor Materials, Federal Institute for Materials Research and Testing (BAM), Richard- \\ Willstätter-Str. 11, D-12489 Berlin, Germany \\ ${ }^{2}$ Div. 8.1 Sensors, Measurement and Testing Methods, Federal Institute for Materials Research and \\ Testing (BAM), Unter den Eichen 87, 12205 Berlin \\ ${ }^{3}$ Div. 4.2 Materials and Air Pollutants, Federal Institute for Materials Research and Testing (BAM), \\ Unter den Eichen 44-46, 12203 Berlin \\ kornelia.gawlitza@bam.de
}

\begin{abstract}
Because ammonia and its reaction products can cause considerable damage to human health and ecosystems, there is a need for reliably operating and reversibly interacting sensor materials to monitor traces of gaseous ammonia in ambient air, which at best can be used on-site for in-the-field measurements. Herein, the development of a sensor material for gaseous ammonia in the lower ppm to ppb range using optical fluorescence as transduction mechanism is presented. A fluorescent dye, which shows reversible fluorescence enhancement in the presence of ammonia is incorporated into a polymer matrix, the latter to ensure the accumulation of ammonia. The sensor material is integrated into a prototype of a miniaturized sensor device, facilitating long-term operation. To calibrate the optical sensor system a gas standard generator, producing standard gas mixtures, is used, leading to a sensitivity down to lower ppm concentrations of ammonia.
\end{abstract}

Keywords: ammonia gas sensor,fluorescence, air quality monitoring,standard gas generator,miniaturized sensor device.

Ammonia is a widely used colorless toxic gas with a specific odor, pollution by which is not only critical for agriculture and industry but also presents a hazard in urban areas. The threshold limit value (TLV) up to which workers may be repeatedly exposed to ammonia daily without adverse effect provided by the American Conference of Governmental Industrial Hygienists (ACGIH) is $35 \mu \mathrm{mol} \mathrm{mol}{ }^{-1}$ (35 ppm). ${ }^{[1]}$ Beyond this limit, human exposure to ammonia can cause conjunctivitis, vomiting and irritation of the throat. There are ammonia emission reduction measures for the areas agriculture, energy, industrie and trafficin the EU. This measure are set in EU-directives for ambient air quality. ${ }^{[2-3]}$ However, the Technical Instructions on Air Quality Control in Germany define that below a concentration of $14 \mathrm{nmol}$ $\mathrm{mol}^{-1}(14 \mathrm{ppb})$ in air no considerable damage of the environment is expected. Hence, sensor systems for gaseous ammonia in air being sensitive in the lower $\mathrm{ppb}$ to $\mathrm{ppm}$ range can help in a permanent monitoring of air quality.
Several sensitive and reliable gas sensors based on measurement methods like electrochemistry, surface acoustic waves and surface plasmon resonance are available. ${ }^{[4-7]}$ Besides a high sensitivity, for gas sensing applications, the sensor should satisfy several requirements such as low cost, ease of fabrication, fast response time, miniaturization as well as the option for on-site use by untrained personnel. ${ }^{[8-9]}$ The use of optical fluorescence as transduction mechanism is highly promising due to its intrinsically high sensitivity and high spatial resolution.[10] To date, a variety of fluorescent turn-on type sensors have been developed for sensing ammonia in solution, ${ }^{[11-13]}$ however, it is more challenging to design such sensors for the detection in the gas phase. ${ }^{[14]}$ Herein, we present first attempts to the design of a miniaturized sensor device for the fluorescence-based long-term monitoring of gaseous ammonia at low concentrations (ppm range). 
The basic component of such a sensor is the fluorescent signaling unit which should exhibit high photostability, high fluorescence quantum yields (QY) and excitation and emission maxima at reasonably long wavelengths in the visible spectral range. Referring to the mentioned properties, dye 1 (Fig. 1) is a promising candidate and shows the typical characteristics of the 1,3,5,7-tetramethyl-2,6diethyl-boron-dipyrromethene (BODIPY) core, i.e., strong lowest-energy absorption and intense emission bands centered at 529 and $545 \mathrm{~nm}$, respectively.[15] We chose the hexaalkylated core because it is known to be the brightest and most photostable one among the core-alkylated BODIPYs. The neutral state is the highly fluorescent ON state while protonation of the pyridine- $\mathrm{N}$ produces a strong quenching. Due to a $\mathrm{p} K_{\mathrm{a}}$ of 2.15 the presence of ammonia leads to a deprotonation of the dye molecule, leading to an increase in fluorescence.

Since the chemical nature of the BODIPY core is ideally suited for steric embedding into polar matrixes while leaching is avoided and the enrichment of gaseous ammonia is enabled, 1 was embedded into a thin polymer film.

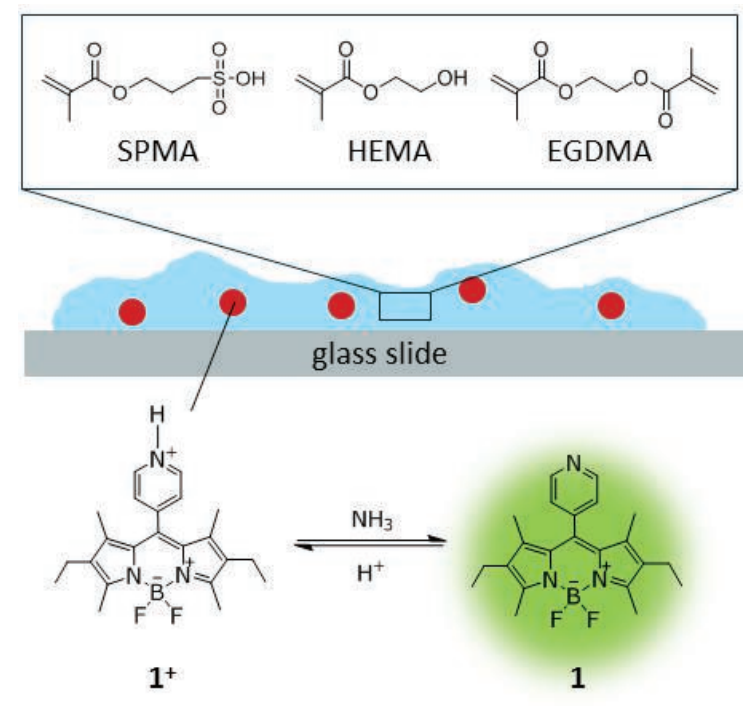

Fig. 1: Scheme of sensor material with BODIPY dye 1 embedded in a polymer matrix composed of 3sulfopropyl methacrylic acid (SPMA), 2-hydroxylethyl methacrylate (HEMA) and ethylene glycol dimethacrylate (EGDMA).

A suitable matrix was prepared by covalently attaching a thin polymer film onto a glass slide, employing 2-hydroxylethyl methacrylate (HEMA) as comonomer and ethylene glycol dimethacrylate (EGDMA) as cross-linker to reach an optimal environment for the dye on the one hand while still being polar enough for accumulation of ammonia. Since long-term monitoring of the analyte is aimed at, a reversible protonation of the dye in the polymer matrix is needed. Hence, sulfopropyl methacrylic acid (SPMA) was used as acidic comonomer (Fig. 1).

Different amounts of SPMA were integrated into the polymer film to obtain the optimal concentration, able to protonate the dye while not lowering the sensitivity due to reaction with ammonia. Figure 2 shows the prepared sensor materials with concentrations of SPMA from 1 mol-\% up to 50 mol- $\%$ relating to HEMA, excited with a UV lamp ( $\lambda_{\text {ex }} 365$ nm, Fig. 2 top) as well as the corresponding emission spectra ( $\lambda_{\text {ex }} 500 \mathrm{~nm}$, Fig. 2 bottom). Because the protonated form of 1 is required to detect the analyte, we chose $15 \mathrm{~mol}-\%$ of SPMA as the optimal concentration as it is the lowest concentration of SPMA that almost quantitatively quenches the emission.
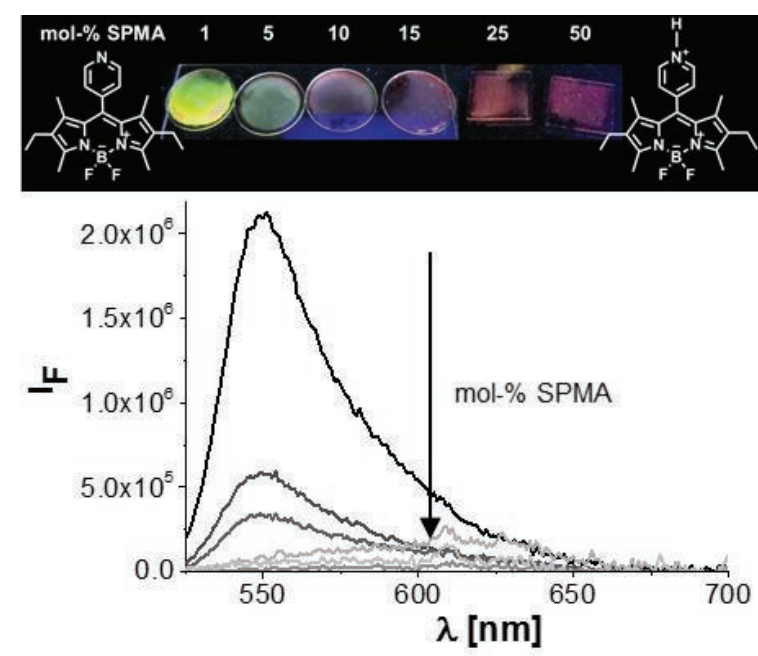

Fig. 2: Images excited with a UV lamp ( $\lambda_{e x}$ $365 \mathrm{~nm}$, top) and emission spectra ( $\lambda_{\text {ex }} 500 \mathrm{~nm}$, bottom) of sensor material as a function of the amount of sulfonic acid in the polymer matrix.

In a next step, the emission spectra of the sensor material in absence and presence of ca. $3 \mathrm{mmol} \mathrm{mol}^{-1}$ gaseous ammonia were recorded and are shown in Figure 3. When ammonia is present a strong increase in the emission band at $550 \mathrm{~nm}$ is observed, which also can be seen by irradiation with UV light (Fig. 3). The glass slide was heated to $90^{\circ} \mathrm{C}$ for $5 \mathrm{~min}$ to accelerate the evaporation of ammonia. This regeneration step restores the OFF state, qualifying the sensor material for reversible detection of gaseous ammonia. 
One requirement on a sensor that has to be suitable for monitoring air quality is a reproducible production of the sensor material itself. Hence, 10 slides were prepared in parallel, followed by performing fluorescence measurements first in absence and then in presence of gaseous ammonia (ca. $3 \mathrm{mmol}$ $\mathrm{mol}^{-1}, \lambda_{\text {ex }} 500 \mathrm{~nm}$ ). To obtain comparable results the ratios of the fluorescence intensities in presence and absence of the analyte were calculated, yielding an average analyteinduced quenching factor of $5.3 \pm 1.5$.

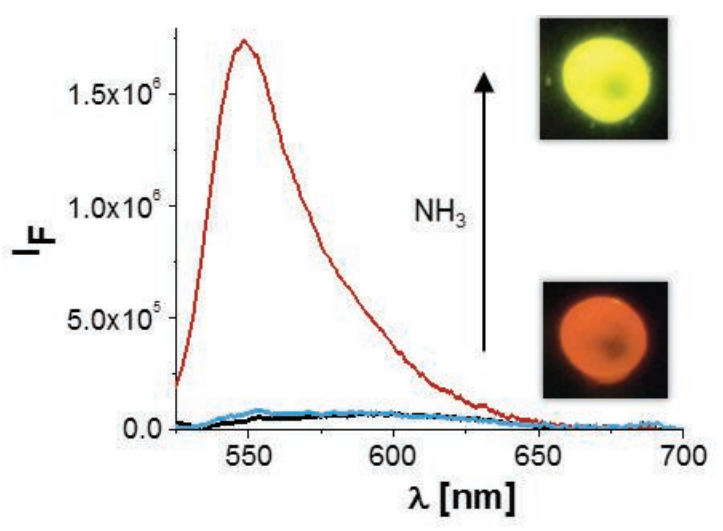

Fig. 3: Emission spectra ( $\left.\lambda_{\text {ex }} 500 \mathrm{~nm}\right)$ of sensor material in absence and presence of gaseous ammonia (ca. 3 mmol mol-1): dry slide after preparation (black line), with ammonia (red line) and after removal of ammonia and heating for $5 \mathrm{~min}$ at $90^{\circ} \mathrm{C}$ (blue line).

Besides the development of a sensitive and reversible sensor, the integration of the sensor material into a miniaturized device is addressed. Therefore, a prototype of a miniaturized hand-held instrument was developed, enabling a straightforward and long-term recording of the measurement signal. ${ }^{16]}$ The left image in Figure 4 shows the main part of the miniaturized sensor. The trained funnel of the measuring head is heated which ensures that the analyte is not deposited on the walls and reaches the sensing layer. At the same time, temperature control in the measurement compartment is achieved. The transparent glass slides as support for the thin fluorescent sensory films permit direct fluorescence signal collection. In more detail, the analyte-induced fluorescence changes of the sensor layer are measured by a photomultiplier tube (PMT) as the detector, processed by a software and displayed on a screen. The miniaturized optical setup comprises of an LED excitation source and the PMT arranged perpendicularly to it.
To qualify the gas sensor for the intended performance, the system must be tested for all the conditions that are relevant for the sensor's behaviour, providing essential information on diverse measurement scenarios and allowing for final sensor optimization.

The gas sensors were calibrated and tested with a system that allows to generate test gas mixtures of defined composition dynamically from appropriate parent gases in cylinders and to transfer them to the measuring device through tubing. The gas blending system allows for continuous variation of the mixture's composition, including humidification, in a broad dynamic range. Gas blending was performed with mass-flow controllers (MFC), which control four different gas streams. The blending process and the resulting composition were regulated by varying the gas flow through the MFCs. The system can generate gas mixtures containing simultaneously up to three different test gases, an inert carrier gas (synthetic air or nitrogen) and humidity. The humidification of the gas mixture is based on the saturation method using a glass bubbler. The humidified carrier gas was cooled down in a gas cooler to adjust the dew point. Finally, the humidified carrier gas was mixed with the test gas, and dry inert carrier gas was added. Different experimental set-ups are possible for test-gas mixing. A personal computer controls all parts of the system via an IEEE-bus net. The tests' output data were collected and visualised in real time and recorded on general laboratory software platforms (LabView, Excel). The gas mixtures' humidity was controlled by a chilled mirror hygrometer. ${ }^{[17]}$ The stainless-steel supply lines have an inner diameter of $4 \mathrm{~mm}$ and tube connections by Swagelok.

The ammonia containing gas mixture in air was diluted in air and in the experiments, the flow

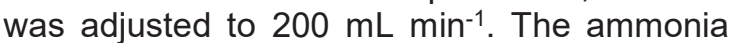
amount fractions used here were covered the range of 0 to $100 \mathrm{ppm}$ with an expanded relative uncertainty of $3 \%$ (Tab. 1) and without humidification.

The computer controlled test facility uses a specific program based on LabView both, for gas generation and gas concentration as a function of time and for data acquisition. The frequency of the latter is determined by the sensor and the application and was set to recording a data point every $2 \mathrm{~s}$ here.

First attempts to determine the sensitivity of the sensor material have been carried out using a prototype of the miniaturized hand-held device in combination with the standard gas 
Tab. 1: Concentrations of gaseous ammonia used for the calibration of the sensor and slopes of the intensity increase for each concentration

\begin{tabular}{|c|c|c|}
\hline $\mathrm{C}_{\mathrm{NH} 3}[\mathrm{ppm}]$ & Slope & $\begin{array}{c}\text { Standard } \\
\text { deviation }\end{array}$ \\
\hline 0 & 0.00 & 0.00 \\
\hline 3 & 0.44 & 0.11 \\
\hline 5 & 0.58 & 0.11 \\
\hline 10 & 1.00 & 0.04 \\
\hline 20 & 2.00 & 0.14 \\
\hline 50 & 4.36 & 0.26 \\
\hline 75 & 5.89 & 0.48 \\
\hline 100 & 6.21 & 0.48 \\
\hline
\end{tabular}

generator. Concentrations of the gaseous analyte from 3 to $50 \mathrm{ppm}$ were passed over the sensor material with a constant flow rate of 200 $\mathrm{mL} \mathrm{min}^{-1}$ for $60 \mathrm{~min}$. In between each concentration, the gas was changed to synthetic air, also using a constant flow rate of $200 \mathrm{~mL} \mathrm{~min}-1$ for $60 \mathrm{~min}$, to flush the material. The results of the duplicate measurements are shown in Figure 4 (middle) representing a response time of roughly $1 \mathrm{~min}$. Obviously, the sensor material gets saturated for each concentration making it useless to derive a calibration curve from the maximum signal reached. Instead, the slope of the signal increase was evaluated for each concentration and plotted as shown in Figure 4 (right). An additional measurement with the same parameters was performed for 75 and 100 ppm. The calibration resulted in a linear response from concentrations of $3 \mathrm{ppm}$ up to $75 \mathrm{ppm}$. To determine the limit of quantitation and the dynamic range further down into the ppb range, additional experiments are currently being conducted.

Our recent work showed the first steps towards the development of a sensitive miniaturized sensor device for the detection of gaseous ammonia at low concentrations during longterm monitoring of air quality in agricultural and urban areas. A fluorescent dye was embedded into a thin polymer film fixed to a glass slide to obtain optimal conditions. While the emission of the fluorescent dye is increased due to deprotonation in presence of ammonia, the polar polymer film ensures the enrichment of ammonia from air. The sensor material was successfully incorporated into a hand-held device which easily can be used on-site by untrained personnel. A standard gas generator was used to determine the concentration range of the sensor material. As a conclusion, the slope of the signal intensity increase must be used to calculate the corresponding concentration of gaseous ammonia. Although the first steps toward the development of a sensor for the long-term monitoring of gaseous ammonia in air have been successfully completed, performance assessment is still ongoing especially with regard to the exact working range and the long-term stability, possibly involving additional optimization loops of the sensor. In addition, kinetics and crossselectivity studies will complement the development.

In conclusion, a promising sensor material is presented, possessing high potential for the future control of air quality.
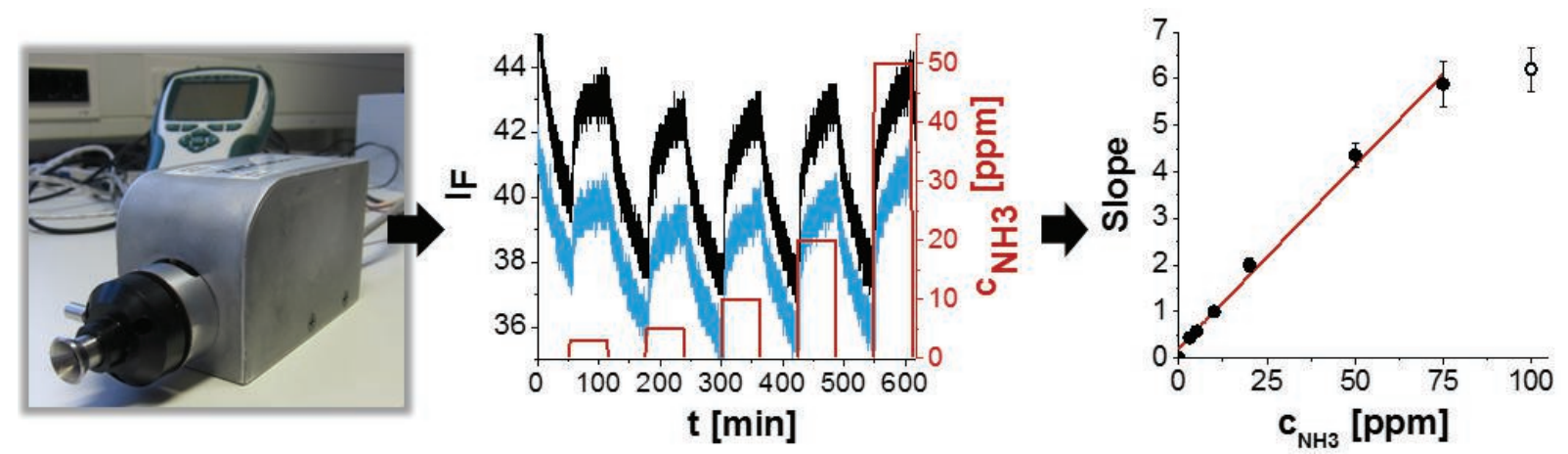

Fig. 4: Prototype of a hand-held device (left), duplicate intensity measurements (blue and black line) of the sensor material with the miniaturized prototype at different ammonia concentrations (3 ppm, $5 \mathrm{ppm}, 10 \mathrm{ppm}, 20 \mathrm{ppm}, 50 \mathrm{ppm}$ ) (middle) and calibration curve determined by the slope of the intensity increase for each concentration (right). 


\section{References}

[1] NIOSH Pocket Guide to Chemical Hazards, NIOSH, (2005).

[2] Directive 2008/50/EC of the European Parliament and of the Council of 21 May 2008 on ambient air quality and cleaner air for Europe, Official Journal of the European Union, (2008).

[3] Das Europäische Parlament und der Rat der Europäischen Union, Richtlinie (EU) 2016/2286 | Reduktion der nationalen Emissionen bestimmter Luftschadstoffe, zur Änderung der Richtlinie 2003/35/EG und zur Aufhebung der Richtlinie 2001/81/EG, Amtsblatt der Europäischen Union, (2016-12-14).

[4] S. M. Kanan, O. M. El-Kadri, I. A. AbuYousef, M. C. Kanan, Sensors 9, 8158-8196,

(2009); doi:10.3390/s91008158.

[5] S. H. Wang, C. Y. Shen, J. M. Su, S. W. Chang, Sensors 15, 7084-7095, (2015); doi:10.3390/s150407084.

[6] D. Schepers, G. Schulze, W. Frenzel, Analytica Chimica Acta 308, 109-114, (1995);

[7] B. Liu, X. Chen, H. Cai, M. Mohammad Ali, X. Tian, L. Tao, Y. Yang, T. Ren, Journal of Semiconductors 37, 021001, (2016); doi:10.1088/16744926/37/2/021001.

[8] J. Homola, S. S. Yee, G. Gauglitz, Sensors and Actuators B 54, 3-15, (1999);

[9] D. Zhang, Y. e. Sun, C. Jiang, Y. Zhang, Sensors and Actuators B: Chemical 242, 15-24, (2017); doi:10.1016/j.snb.2016.11.005.

[10] T. Ozawa, H. Yoshimura, S. B. Kim, Analytical chemistry 85, 590-609, (2013); doi:10.1021/ac3031724.

[11] X. Chen, Y.-j. Dai, Z. Li, Z.-x. Zhang, X.-r. Wang, Fresenius' Journal of Analytical Chemistry 370, 1048-1051, (2001);

[12] K. Waich, T. Mayr, I. Klimant, Talanta 77, 66-72, (2008); doi:10.1016/j.talanta.2008.05.058.

[13] G. J. Mohr, S. Draxler, K. Trznadel, F. Lehmann, M. E. Lippitsch, Analytica Chimica Acta 360, 119-128, (1998);

[14] Y. Takagai, Y. Nojiri, T. Takase, W. L. Hinze, M. Butsugan, S. Igarashi, The Analyst 135, 1417-1425, (2010); doi:10.1039/b922842j.
[15] R. Gotor, P. Ashokkumar, M. Hecht, K. Keil, K. Rurack, Analytical chemistry 89, 8437-8444, (2017); doi:10.1021/acs.analchem.7b01903.

[16] R. Noske, BAM Berlin, Tragbare Vorrichtung zum Messen von flüchtigen chemischen Stoffen, DE202016102767, (2016).

[17] M. Lang, U. Banach, K. Nörthemann, A.-K. Gerlitzke, M. Milstrey, R. Kaufer, M. Woratz, T. Hübert, W. Moritz, Sensors and Actuators B: Chemical 187, 395-400, (2013); doi:10.1016/j.snb.2012.12.081. 